\title{
National Innovation-Oriented City Evaluation Study Based on Two-Stage DEA Model
}

\author{
Xianbiao Wei, Yuzhen Duan, Mo Wang, Junxing Zhou, Xiaobao Peng \\ University of Science and Technology of China, Hefei, China \\ Email: wxb5316@163.com
}

How to cite this paper: Wei, X.B., Duan, Y.Z., Wang, M., Zhou, J.X. and Peng, X.B. (2017) National Innovation-Oriented City Evaluation Study Based on Two-Stage DEA Model. Journal of Applied Mathematics and Physics, 5, 1855-1873.

https://doi.org/10.4236/jamp.2017.59156

Received: March 28, 2017

Accepted: September 25, 2017

Published: September 28, 2017

Copyright $\odot 2017$ by authors and Scientific Research Publishing Inc. This work is licensed under the Creative Commons Attribution International License (CC BY 4.0).

http://creativecommons.org/licenses/by/4.0/

\begin{abstract}
The research on the evaluation indicator system of innovation-oriented cities has a long history. It presents different characteristics in different countries or regions. In 2006, China proposed the national strategy to build an innovationoriented nation and subsequently approved more than 60 pilot cities in the country. The research on China's innovation-oriented city assessment system is also increasing. On the basis of predecessors, this paper constructs innovationoriented city evaluation indicator system with more links based on innovation link. It has three categories with 44 indicators in total according to input, intermediate output and final output. It creatively introduces in two-stage DEA model on sharing input and constructs the evaluation model based on the above evaluation indicator system. This paper makes an empirical analysis on the innovation-oriented cities in Yangtze River Delta including Hefei, arrives at innovation efficiency difference and puts forward some countermeasures and suggestions for the analysis results.
\end{abstract}

\section{Keywords}

DEA, National Innovation-Oriented Cities, Assessment

\section{Introduction}

As an important factor to drive economic and social development, innovation has been widely regarded by scholars at home and abroad. With the continuous development of China's economy and the constantly changing of China's economic structure and economic growth driving forces, the importance of innovation-oriented city construction is becoming more and more prominent. An innovation-oriented city conforms to the requirement of modern economic development. It regards innovation as core driving force for development of a city and speeding up development of the regional industry through the way 
of innovation. It helps to improve the scientific and technological innovation ability, optimize configuration of a city's internal production resource factors and then promote and coordinate the development of the city's social economy in an all-round way. In order to improve the independent innovation ability and international competitiveness of a city, many cities in our country have also successively put forward the objectives and tasks to construct innovation-oriented cities. In fact, innovation-oriented cities require being smart, then only to survive as platforms that suggest economic, urban, and environmental well being [1]. Research on innovation-oriented city construction in China has important practical significance. Evaluation on the efficiency of city innovation can provide a basic criterion for scientized and rationalized construction of innovation-oriented cities and give a reference to cities' rational allocation of resources on the premise of maximized innovative efficiency. At the same time, it is easier for efficiency evaluation to find the problems in the evaluation process faced by innovation-oriented cities construction so as to facilitate policy-making and manage the countermeasures.

In many analytical methods, we adopt the Data Envelopment Analysis (DEA). DEA is a mathematical linear programming model with non-parameter evaluation, which focuses on the evaluation on systematic input and output efficiency. DEA's goal is to make the evaluation system to meet a maximized internal benefit. Its advantage is that there is no need to consider the production function relationship between input and output. It only needs to calculate the input and output efficiency in every part. There is also no need to determine the weight of the upper indicator in advance to avoid the adverse impact caused by the inaccurate upper indicators on the determination to the weight of lower indicators. Creative cities in the modern world are typically organized around production systems marked by shifting interfirm networks and flexible labor markets of the sorts described above [2]. The indicator weight calculated by DEA can reflect the contribution of indicators more. However, DEA can only evaluate the efficiency of initial inputs and final outputs without taking into account the internal development logic from input to output. Therefore, when proposing the evaluation model of innovation-oriented city development efficiency, we will divide the generation of innovation efficiency into stages for evaluation, bring in intervening variables to control and ensure the whole process of innovation efficiency evaluation. Combining with the inherent logic of urban innovation, we will generally classify element, resource and performance indicators of innovation-oriented city development according to input, intermediate output (re-input) and final output, and finally divide them into innovative input, innovative intermediary services, intellectual achievements transformation and innovative performance, namely three comprehensive secondary indicators. Traditional methods of innovation system analysis that mainly focus on the structure of innovation systems have proven to be insufficient [3]. According to the specific content of the innovative input and in order to meet the needs of re- 
sources for innovative development, the secondary indicator, innovative input, can be divided into innovative capital input, innovative talent input, innovative environment construction and innovative policy support four third-level indicators. The intermediary service and intellectual achievements transformation are divided into intermediary platform construction, industry-university-research cooperation ability and innovation diffusion absorption ability three third-level indicators in accordance with the basic model of collaborative innovation and open innovation. According to the effect of innovation-oriented city development, the innovative output indicator can be divided into four third-level indicators: technological innovation effect, economic pull effect, social contribution effect and ecological construction effect.

Scholars have evaluated innovation-oriented cities from multiple perspectives. At the earliest, Landry (1995) has evaluated innovation-oriented city from the perspective of the basic elements of innovation-oriented city development. The evaluation mainly includes four aspects: technology, social development, culture atmosphere and institutional environment. Landry has constructed innovationoriented city's vitality evaluation matrix (Bianchini F \& Landry C, 1995). It includes nine indicators: city scale effect, diversity, convenience, safety and security, identity and personality, innovativeness, connection and synergy, competitive capacity and organization ability. After that, many scholars have developed the innovation-oriented city evaluation indicator from different angles on the four aspects. From the perspective of technical personnel, the development of an innovation-oriented city has $3 \mathrm{~T}$ indicators, namely, technology, talent and tolerance. It is said that those three indicators directly affect the development performance of an innovation-oriented city. Technology is the core indicator of innovation; talents are the premise of technology development; tolerance is more about to consider how to build institutional environment and development platform for innovation from the perspective of developing technology and training talents. Then, that indicator has gradually developed into innovation index for evaluating innovation-oriented cities (Florida, 2002). From the angle of innovation management, public service innovation in innovation-oriented city is an important aspect to evaluate the city's innovation management level, which mainly includes joint evaluation on social innovation and technological innovation. It calls for the service innovation as a complete set of innovative relations. A certain skills and economic basis is required for technology integration under social innovation. Effective evaluation on open innovative services is an integration of evaluations on all stakeholders who are capable of evaluation (K Paskaleva \& I Cooper, 2014). From the perspective of innovation agglomeration, James Simmie (2001) comprehensively evaluates the cooperation ability and competitive ability of innovation-oriented cities from industrial agglomeration, market concentration and urban agglomeration. From the angle of innovation capability, the combination of national innovation system and the coordinated development of urban innovation are used to evaluate innovation ability 
promotion and economic sustainable development. The main indicators include total urban population, total economic development, labor force structure and technology R\&D expenditures, etc. (James Simmie, 2001).

Scholars have constructed some innovation-oriented city evaluation systems. From the perspective of foreign scholars, the earliest to evaluate city innovation ability is Robert Huggins Association in Britain. Its main function is to build the indicator system to evaluate the intellectual output and science and technology influence of cities. It focuses on the competitiveness of the city. Later, the indicator evaluation system of city innovation capability and its framework have been perfected constantly. Among many indicators, European Innovation Scoreboard (EIS) is relatively common in utility. That index conducts its evaluation mainly around resources and policy support, which mainly includes three aspects: a city's development environment, subject's behavior during the development of an innovation-oriented city and the development achievements of an innovation-oriented city. Among them, subject's behavior mainly focuses on the enterprise subject; development achievements mainly focus on the innovation output and economic growth. It can be seen from EIS' evaluation system that the scope of its evaluation has certain limitations. The scope of the evaluation's influence factors is limited; the evaluation's subject is singular; the performance output concerned is over concentrated on economic effect. At present, the evaluation system is under revising and the current indicators has increased to 29, covering many aspects like economic development, employment, scientific research, education, social welfare and social stability. Another commonly used indicator is $O E C D$ 's Scientific Technology and Industrial Innovation Integral Card. It constructs the STI innovation indicator system, whose main function is the centralized evaluation on technology and intellectual output. It pays a heavy attention to knowledge and intellect's influence on production and development. In 2010, the World Economy Forum (WEF) released Innovation Capacity Indicator (ICI). ICI is a composite Indicator including elements such as institution, legal system. It carries out a systematic evaluation on innovation-oriented cities mainly from institutional environment, human capital, social participation, control and legal framework, $\mathrm{R} \& \mathrm{D}$ situation and application of informative communication technology. The indicator is currently widely used internationally.

Presently, for research on the evaluation on the regional innovation efficiency based on DEA method, relevant scholars more set their hands to the construction of evaluation indicator system, using each indicator to analyze regional innovation ability in each region. On the basis of DEA method, Dai Ming, et al. (2011) builds model programming to innovative input of the complicated supporting system in innovation-oriented cities and the innovative output under that innovative system with the reference of existing innovation evaluation indicator system. They carry out empirical analysis and performance evaluation on 17 national innovative pilot cities. Hou Fenghua et al. (2008) has established a regional innovation ability evaluation indicator system including 22 indicators 
and evaluated the innovation ability of 10 provinces and cities in eastern China. Liu Shunzhong et al. (2007) establishes input and output indicator by using DEA method and evaluates the regional innovation performance of China. Guan Jiancheng, et al. (2005) analyzes the influence of innovative system's resources allocation in regional innovation institutions on innovation performance in China with DEA method. Ma Xiuzhen, et al. (2014) uses DEA method to empirically analyze the relative efficiency of technology input and output in Qingdao from 2001 to 2011. However, most studies on innovation-oriented cities only settle the innovation on the individual economic subject level and the development results of specific innovation subject. They do not consider innovation as a resource integration and coordination activity, lacking of system and development point of view.

\section{China's Innovation-Oriented City Input and Output Indicator System}

This paper studies the overall development efficiency of an innovation-oriented city, generally classifies element, resource and performance indicators of the development of innovation-oriented cities into three general secondary indicators like innovative input, innovative intermediary services, intellectual achievements transformation and innovative performance according to the input, intermediate output (re-input) and final output. According to the specific innovation content, in order to meet the resources needs of innovation development, the secondary indicators innovation input is divided into innovative capital input, innovative talents input, innovative environment construction and innovative policy support. Innovation is not a stable unit of analysis, since it operates at an interface by definition [4]. Innovation results from the recombination of knowledge held by the partners to the collaboration [5]. The intermediary service and intellectual achievements transformation are divided into intermediary platform construction, industry-university-research cooperation ability and innovation diffusion absorption ability in accordance with the basic model of collaborative innovation and open innovation. The issue of transforming the achievements of technological innovation into intellectual property is closely associated with the strategy of strengthening technological innovation, developing high technology and realizing industrialization [6]. According to development effect of innovation-oriented city, the innovation output indicator can be divided into four third-level indicators: technological innovation effect, economic pull effect, social contribution effect and ecological construction effect. 44 forth-level indicators are set respectively from 11 aspects like capital and talents input, environmental construction and policy support, intermediate platform, industry-university-research cooperation, innovative network, scientific and technological innovation achievements and ecological construction. A nation's standard of living in the long term depends on its ability to attain a high and rising level of productivity in the industries in which its firms compete [7]. Those fourth-level indicators are combined 
with basic factors and environmental supporting capacity analysis, performance analysis, development path analysis, innovation network analysis, innovation chain construction analysis. Evaluation indicators are shown in Table 1.

The first-level indicators are determined to be innovative input, innovative intermediary service and intellectual achievements transformation and innovative output, which are mainly based on system principle of indicator institution. Namely, the process of determining the indicator is not to simply list those indicators but to consider connection and integrity between indicators and to pay attention to the combination of micro and macro indicators. When innovation-oriented city' capacity is evaluated, innovative input, innovative intermediary services and innovative performance output indicator are organically organized, combining the innovation system theory. They offer a framework for evaluating innovation performance: the innovation value chain. It comprises the three main phases of innovation (idea generation, conversion, and diffusion) as well as the critical activities performed during those phases (looking for ideas inside your unit; looking for them in other units; looking for them externally; selecting ideas; funding them; and promoting and spreading ideas companywide) [8]. Multi-agent, multi-level and multi-dimensional innovative factors are considered comprehensively. There are a few channels including technoparks, building research platforms with enterprises in different ways, and technology transfer offices to diffuse the knowledge [9]. All main links during an innovation-oriented city's development are holistically analyzed. In terms of innovative input, capital, talent, environment and policy are the most important elements.

In terms of the intermediary service and intellectual achievements transformation, we set platform construction, industry-university-research cooperation ability and innovation diffusion absorption ability as secondary indicators because that process is based on the intermediary service platform's connecting process towards input and output elements. In terms of innovative output, innovation mainly benefits economic and social development through scientific and technological achievements. So, when we study science and technology innovation effect, we also set economic development effect and social contribution effect as secondary indicators. Integrating concept and principle of ecological civilization into innovation-oriented city evaluation system is the key to ensure healthy development of urbanization in China. At present, many cities have no consideration to consequences for the ecological environment during the development, so this paper especially introduces ecological construction effect of innovation-oriented cities into indicator system.

\section{Indicator Weight Determination and DEA Model Construction}

The indicator system set up in the last section consists of 44 evaluation indicators in four levels. According to characteristics of indicators, the relationship 
Table 1. Innovative-Oriented Cities Evaluation Indicators.

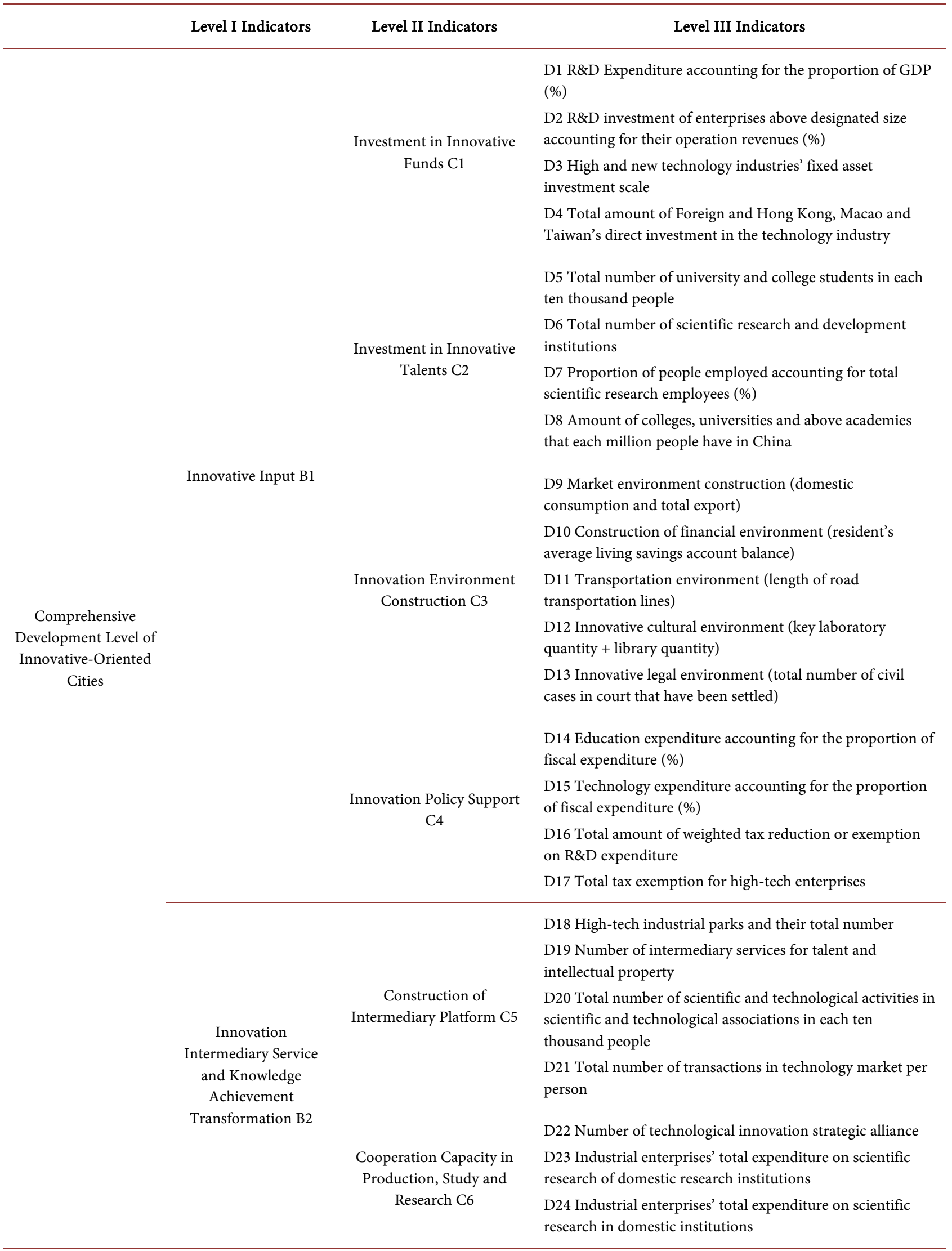




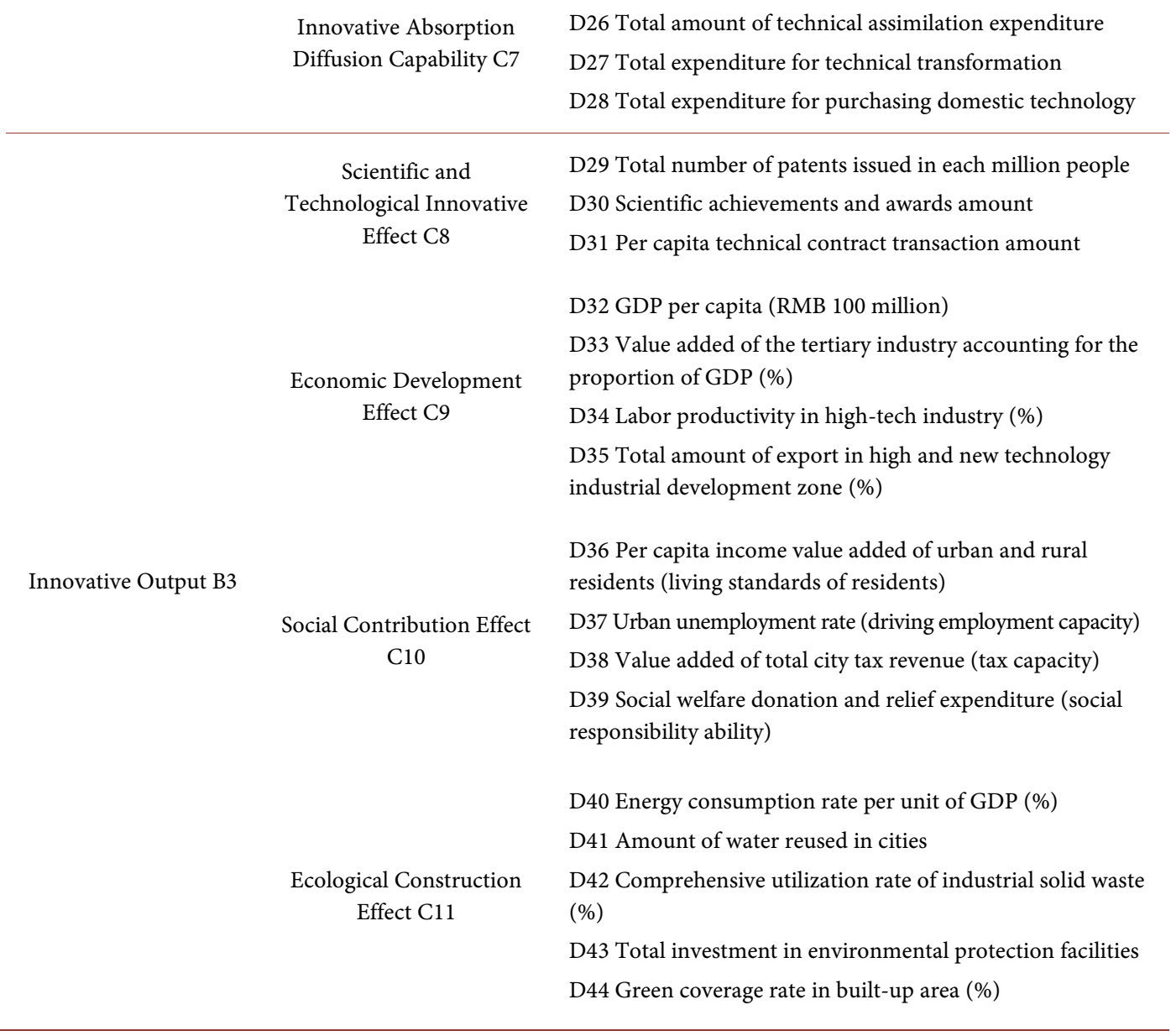

and weight among indicators need to be determined level by level, which can ultimately be evaluated from the whole process of input, intermediary services and output of innovation-oriented city development. The weight reflects the contribution degree from each lower indicator to the upper indicator. The stronger the function is, the greater the weight of the indicator will be. The Global Clusters of Innovation Framework helps us to understand new patterns of innovation and commercialization in existing or emerging highly entrepreneurial agglomerations of businesses [10]. According to the research results of domestic and foreign scholars, there are two main methods to determine those indicators presently: subjective evaluation method and objective evaluation method. But the indicator weight of evaluators determined by subjective evaluation method depends entirely on their own psychological likes and dislikes and value criterion, which has a great deal of uncertainty. So, it is difficult to guarantee the scientific nature, stability, comparability and rationality of the evaluation. Traditional objective evaluation method mainly includes the AHP analytic hierarchy process (AHP), entropy weight method, maximum deviation weight method, variation coefficient method and standard deviation method. But those traditional weight 
determination methods have some defects. Analytic hierarchy process (AHP) is an indicator weight determining method combining subjective evaluation with objective evaluation. Entropy weight method is based on the variability of raw data to determine the weight of indicators. The greater the variation of indicators is, the more information will be reflected out and the bigger the indicator weight will be determined correspondingly. Although this method ensures the objectivity of the data processing, the cause of a big indicator variation is a lot. It is difficult to guarantee and explain the reason for a larger variation is due to a larger contribution from the indicator to the upper indicator. Particularly, when there is a large development difference between two evaluation objects, the evaluation under this method becomes inaccurate and not objective. The corresponding maximum interest margin weighting method, variation coefficient method and standard deviation method all have the above question, so they will not be explained in this paper. For the problems existing in many above evaluation-weighting methods, it can be seen that it should not only guarantee the principle of objective evaluation but also ensure the indicator weight size should show the degree of contribution to upper indicator and embody the real effect of each indicator to innovation and development when the indicator weight method is chosen. Therefore, data envelopment analysis (DEA) is selected in this paper as determination method of indicator weight.

According to the present evaluation decision-making unit $D M U$, supposing that there are $n$ innovation-oriented cities as evaluation objects, any one of the cities $j$ is selected as a basic code of those innovation-oriented cities and $j=1,2,3,4, \cdots, n$. The evaluation of the whole innovation process can be divided into two links. The first link is mainly innovation input indicator's evaluation on intermediary service and platform output efficiency, which includes the specialized inputs in the first stage and the sharing input used together with the second stage. The second stage is mainly intermediary service and intellectual achievements transformation's innovative performance to the final performance. Output of the first stage is to create the ultimate innovation performance so it is added into the performance creation in second stage as a new input. At this point, part of the first stage's sharing input continues to be the input of the second stage. As the intermediate variable, all output in the first stage constitutes the second stage's input.

According to the above evaluation link, each decision-making unit $D M U_{j}(j=1,2,3, \cdots, n)$ has $m$ input indicators during the whole innovation process in total. They are defined as $x_{i j}(i=1,2, \cdots, m)$. Some of those $m$ indicators are just the initial innovative input indictors in the first stage, which can be defined as $x_{i 2 j}\left(i_{1}=1,2,3,4, \cdots, m\right), i_{1} \in I_{1}$; while others are input indicators that are shared by both stages, which can be defined as $x_{i 2 j}\left(i_{2}=1,2,3,4, \cdots, m\right)$, $i_{2} \in I_{2}, \quad I_{1} \cup I_{2}=\{1,2,3, \cdots, m\}$. Given the hysteresis of innovative input and the accessibility of innovative indicator data, the initial innovative input indicator is selected to be the last phase of the current phase. The input in the first link will 
generate $s$ intermediate output correspondingly, which can be defined as $z_{d j}(d=1,2, \cdots, s)$; later, they will be the input of the second stage. This paper assumes that all the intermediate output is the input in the second stage and participate in the achievements creation. At the same time, $t$ performance outputs will be generated at the end of second stage, which is marked as $y_{r j}(r=1,2,3,4, \cdots, t)$. Given the hysteresis of innovative input and the accessibility of innovative indicator data, the selecting phase of the final output indicator is delayed for two phases. The input $x_{i 2 j}\left(i_{2}=1,2,3,4, \cdots, m\right), i_{2} \in I_{2}$ is shared by both stages, so we assume that all $x_{i 2 j}, i_{2} \in I_{2}$ will be divided into two parts to distinguish their proportions in those two inputting stages. One part is $\alpha_{i 2 j} x_{i 2 j}$ while another part is $\left(1-\alpha_{i 2 j}\right) x_{i 2 j}$, among which all $\alpha_{i 2 j}$ must be guaranteed within a certain interval range (note: the weights of input and output are respectively determined as $\left.u_{i 1}, u_{i 2}, \eta_{d}, u_{r}\right)$.

By building the above model, we can not only ensure that the entirety is effective but also ensure that each stage is effective. The related conceptual model is shown in Figure 1.

In order to better measure the efficiency in the two stages' process, we will set a set of optimal weights for the intermediary link to maximize the overall innovation efficiency. Under the assumptions of the scale yield constant CRS, we mark the total innovative efficiency score as two stages' weighted sum:

$$
w_{1} \frac{\sum_{d=1}^{s} \eta_{d} z_{d}}{\sum_{i_{1} \in I_{1}} u_{i 1} x_{i 1}+\sum_{i_{2} \in I_{2}} u_{i 2} \alpha_{i 2} x_{i 2}}+w_{2} \frac{\sum_{r=1}^{t} u_{r} y_{r}}{\sum_{i_{2} \in I_{2}} u_{i 2}\left(1-\alpha_{i 2}\right) x_{i 2}+\sum_{d=1}^{s} \eta_{d} z_{d}}
$$

Among them, $w_{1}+w_{2}=1$.

The definition of the above overall efficiency model can ensure that the overall process is valid and each phase is valid for sure. On the premise of unchanged returns to scale, the holistic input of the overall input process can be expressed as:

$$
\sum_{i_{1} \in I_{1}} u_{i 1} x_{i 1 j}+\sum_{i_{2} \in I_{2}} u_{i 2} x_{i 2 j}+\sum_{d=1}^{s} \eta_{d} z_{d}
$$

The overall output in this process can be directly expressed as:

$$
\sum_{d=1}^{s} \eta_{d} z_{d}+\sum_{r=1}^{t} u_{r} y_{r}
$$

The linear programming model is established as follows:

(Investment in Sharing) $x_{i 2}$

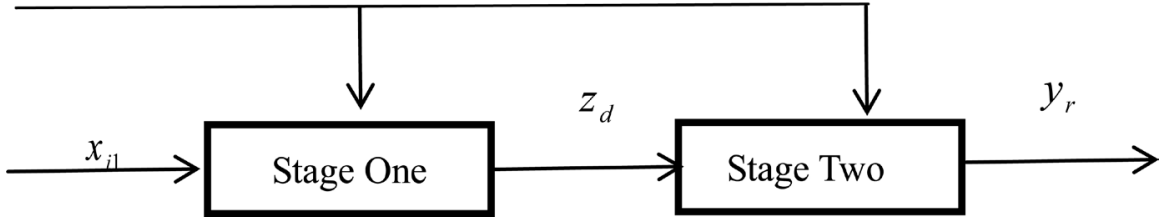

Figure 1. Two-Stage Conceptual Model Diagram. 


$$
\begin{aligned}
& \theta_{0}^{*}=\max \frac{\sum_{d=1}^{s} \eta_{d} z_{d}+\sum_{r=1}^{t} u_{r} y_{r}}{\sum_{i_{1} \in I_{1}} u_{i 1} x_{i 1 j}+\sum_{i_{2} \in I_{2}} u_{i 2} \alpha_{i 2 j} x_{i 2 j}+\sum_{d=1}^{s} \eta_{d} z_{d}} \\
& \text { s.t. } \frac{\sum_{d=1}^{s} \eta_{d} z_{d}}{\sum_{i_{1} \in I_{1}} u_{i 2} x_{i 2 j}+\sum_{i_{2} \in I_{2}} u_{i 2} \alpha_{i 2 j} x_{i 2 j}} \leq 1, j=1,2,3,4, \cdots, n \\
& \sum_{i_{i_{2} \in I_{2}} u_{i 2}\left(1-\alpha_{i 2 j}\right) x_{i 2 j}+\sum_{d=1}^{s} \eta_{d} z_{d}}^{\sum_{r=1}^{t} u_{r} y_{r}} \leq 1, j=1,2,3,4, \cdots, n \\
& L_{i 2 j}^{1} \leq \alpha_{i 2 j} \leq L_{i 2 j}^{2}, j=1,2,3, \cdots, n \\
& u_{i 1}, u_{i 2}, \eta_{d}, u_{r} \geq \varepsilon, i_{1} \in I_{1}, i_{2} \in I_{2}, r=1,2, \cdots, t, d=1,2, \cdots, s
\end{aligned}
$$

Since the above model is a fractional planning, it is difficult to solve. So, the model can be equally transformed by Charnes-Cooper transformation into:

$$
\begin{aligned}
& \theta_{0}^{*}=\max \sum_{d=1}^{s} \pi_{d} z_{d}+\sum_{r=1}^{t} \mu_{r} y_{r} \\
& \text { s.t. } \sum_{d=1}^{s} \pi_{d} z_{d j}-\left(\sum_{i_{1} \in I_{1}} \omega_{i 1} x_{i 1 j}+\sum_{i_{2} \in I_{2}} \omega_{i 2} x_{i 2 j}\right) \leq 0, j=1,2, \cdots, n \\
& \sum_{r=1}^{t} \mu_{r} y_{r j}-\left[\sum_{i_{2} \in I_{2}} \omega_{i 2}\left(1-\alpha_{i 2 j}\right) x_{i 2 j}+\sum_{d=1}^{s} \pi_{d} z_{d j}\right] \leq 0, j=1,2, \cdots, n \\
& \sum_{i_{1} \in I_{1}} \omega_{i 1} x_{i 1}+\sum_{i_{2} \in I_{2}} \omega_{i 2} x_{i 2}+\sum_{d=1}^{s} \pi_{d} z_{d}=1 \\
& L_{i 2 j}^{1} \leq \alpha_{i 2 j} \leq L_{i 2 j}^{2}, j=1,2,3, \cdots, n \\
& \mu_{i 1}, \mu_{i 2}, \omega_{i 1}, \omega_{i 2} \geq \varepsilon, i_{1} \in I_{1}, i_{2} \in I_{2}, r=1,2, \cdots, t, d=1,2, \cdots, s
\end{aligned}
$$

Since there is $\sum_{i_{2} \in I_{2}} \omega_{i 2} \alpha_{i 2 j} x_{i 2 j}$ in the model, the above model is still nonlinear, which needs to be transformed into linear model through $\beta_{i 2 j}=\omega_{i 2 j} \alpha_{i 2 j}$ to solve.

$$
\begin{aligned}
& \theta_{0}^{*}=\max \sum_{d=1}^{s} \pi_{d} z_{d}+\sum_{r=1}^{t} \mu_{r} y_{r} \\
& \text { s.t. } \sum_{d=1}^{s} \pi_{d} z_{d j}-\left(\sum_{i_{1} \in I_{1}} \omega_{i 1} x_{i 1 j}+\sum_{i_{2} \in I_{2}} \beta_{i 2} x_{i 2 j}\right) \leq 0, j=1,2, \cdots, n \\
& \sum_{r=1}^{t} \mu_{r} y_{r j}-\left[\sum_{i_{2} \in I_{2}}\left(\omega_{i 2}-\beta_{i 2 j}\right) x_{i 2 j}+\sum_{d=1}^{s} \pi_{d} z_{d j}\right] \leq 0, j=1,2, \cdots, n \\
& \sum_{i_{1} \in I_{1}} x_{i 1}+\sum_{i_{2} \in I_{2}} \omega_{i 2} x_{i 2}+\sum_{d=1}^{s} \pi_{d} z_{d}=1 \\
& L_{i 2 j}^{1} \omega_{i 2} \leq \beta_{i 2 j} \leq L_{i 2 j}^{2} \omega_{i 2}, j=1,2,3, \cdots, n \\
& \mu_{i 1}, \mu_{i 2}, \omega_{i 1}, \omega_{i 2} \geq \varepsilon, i_{1} \in I_{1}, i_{2} \in I_{2}, r=1,2, \cdots, t, d=1,2, \cdots, s
\end{aligned}
$$

In order to better understand the mechanism of each link, the above overall efficiency is decomposed. On the premise to ensure overall efficiency, the efficiency of the first and second stages is highest. Based on the above model, we bring in two optimal weight $w_{1}^{*}$ and $w_{2}^{*}, w_{1}^{*}=\sum_{i_{1} \in I_{1}} \omega_{i 1}^{*} x_{i 1}+\sum_{i_{2} \in I_{2}} \beta_{i 2}^{*} x_{i 2}$, 
$w_{2}^{*}=1-w_{1}^{*}, \quad w_{i 1}^{*}, w_{i 2}^{*}, \beta_{i 2}^{*}, \pi_{d}^{*}$ is the optimal solution of model $w_{i 1}, w_{i 2}, \beta_{i 2}, \pi_{d}$.

Under the premise that the overall efficiency is optimal, the maximum efficiency of the first phase is guaranteed and the model is as follows:

$$
\begin{aligned}
& \theta_{1}^{*}=\max \frac{\sum_{d=1}^{s} \eta_{d} z_{d}}{\sum_{i_{1} \leq I_{1}} u_{i 1} x_{i 1}+\sum_{i_{2} \in I_{2}} u_{i 2} \alpha_{i 2} x_{i 2}} \\
& \text { s.t. } \frac{\sum_{d=1}^{s} \eta_{d} z_{d j}}{\sum_{i_{1} \in I_{1}} u_{i 1} x_{i 1 j}+\sum_{i_{2} \in I_{2}} u_{i 2} \alpha_{i 2 j} x_{i 2 j}} \leq 1, j=1,2,3, \cdots, n \\
& \frac{\sum_{r=1}^{t} u_{r} y_{r}}{\sum_{i_{2} \in I_{2}} u_{i 2}\left(1-\alpha_{i 2 j}\right) x_{i 2 j}+\sum_{d=1}^{s} \eta_{d} z_{d j}} \leq 1, j=1,2,3,4, \cdots, n \\
& \theta_{0}^{*}=\frac{\sum_{d=1}^{s} \eta_{d} z_{d}+\sum_{r=1}^{t} u_{r} y_{r}}{\sum_{i_{1} \in I_{1}} u_{i_{1}} x_{i 1}+\sum_{i_{2} \in I_{2}} u_{i 2} \alpha_{i 2} x_{i 2}+\sum_{d=1}^{s} \eta_{d} z_{d}} \\
& w_{1}^{*} \frac{\sum_{d=1}^{s} \eta_{d} z_{d}}{\sum_{i_{1} \in I_{1}} u_{i 1} x_{i 1}+\sum_{i_{2} \in I_{2}} u_{i 2} \alpha_{i 2} x_{i 2}} \leq \theta_{0}^{*} \\
& L_{i 2 j}^{1} \leq \alpha_{i 2 j} \leq L_{i 2 j}^{2}, j=1,2,3, \cdots, n \\
& u_{i 1}, u_{i 2}, u_{r}, \eta_{d} \geq \varepsilon, i_{1} \in I_{1}, i_{2} \in I_{2}, r=1,2, \cdots, t, d=1,2, \cdots, s
\end{aligned}
$$

Transform the above model into a linear model as follows:

$$
\begin{aligned}
& \theta_{1}^{*}=\max \sum_{d=1}^{s} \pi_{d} z_{d} \\
& \text { s.t. } \sum_{d=1}^{s} \pi_{d} z_{d j}-\left(\sum_{i_{1} \in I_{1}} \omega_{i 1} x_{i 1 j}+\sum_{i_{2} \in I_{2}} \beta_{i 2} x_{i 2 j}\right) \leq 0, j=1,2, \cdots, n \\
& \sum_{r=1}^{t} \mu_{r} y_{r j}-\left[\sum_{i_{2} \in I_{2}}\left(\omega_{i 2}-\beta_{i 2 j}\right) x_{i 2 j}+\sum_{d=1}^{s} \pi_{d} z_{d j}\right] \leq 0, j=1,2, \cdots, n \\
& \left(1-\theta_{0}^{*}\right) \sum_{d=1}^{s} \pi_{d} z_{d}+\sum_{r=1}^{t} \mu_{r} y_{r}-\theta_{0}^{*}\left(\sum_{i_{1} \in I_{1}} \omega_{i 1} x_{i 1}+\sum_{i_{2} \in I_{2}} \omega_{i 2} x_{i 2}\right)=0 \\
& w_{1}^{*} \sum_{d=1}^{s} \pi_{d} z_{d} \leq \theta_{0}^{*} \\
& \sum_{i_{1} \in I_{1}} \omega_{i 1} x_{i 1}+\sum_{i_{2} \in I_{2}} \beta_{i 2} x_{i 2}=1 \\
& L_{i 2 j}^{1} \omega_{i 2} \leq \beta_{i 2 j} \leq L_{i 2 j}^{2} \omega_{i 2}, j=1,2,3, \cdots, n \\
& \mu_{r}, \pi_{d}, \omega_{i 1}, \omega_{i 2} \geq \varepsilon, i_{1} \in I_{1}, i_{2} \in I_{2}, r=1,2, \cdots, t, d=1,2, \cdots, s
\end{aligned}
$$

The efficiency score of the first stage can be obtained through the calculation of the above model and the efficiency of the first stage are brought into the formula:

$$
\theta_{2}^{*}=\frac{\theta_{0}^{\prime \prime}-\theta_{1}^{\prime \prime} \omega_{1}^{\prime \prime}}{\omega_{2}^{\prime \prime}}
$$

Then, the efficiency of the second stage can be gained. Similarly, the efficiency 
linear model of the second stage can be obtained:

$$
\begin{aligned}
& \theta_{2}^{*}=\max \sum_{r=1}^{t} \mu_{r} y_{r} \\
& \text { s.t. } \sum_{d=1}^{s} \pi_{d} z_{d j}-\left(\sum_{i_{1} \in I_{1}} \omega_{i 1} x_{i 1 j}+\sum_{i_{2} \in I_{2}} \beta_{i 2 j} x_{i 2 j}\right) \leq 0, j=1,2, \cdots, n \\
& \sum_{r=1}^{t} \mu_{r} y_{r j}-\left[\sum_{i_{2} \in I_{2}}\left(\omega_{i 2}-\beta_{i 2 j}\right) x_{i 2 j}+\sum_{d=1}^{s} \pi_{d} z_{d j}\right] \leq 0, j=1,2, \cdots, n \\
& \left(1-\theta_{0}^{*}\right) \sum_{d=1}^{s} \pi_{d} z_{d}+\sum_{r=1}^{t} \mu_{r} y_{r}-\theta_{0}^{*}\left(\sum_{i_{1} \in I_{1}} \omega_{i 1} x_{i 1}+\sum_{i_{2} \in I_{2}} \omega_{i 2} x_{i 2}\right)=0 \\
& w_{2}^{*} \sum_{d=1}^{s} \mu_{r} y_{r} \leq \theta \\
& \sum_{i_{2} \in I_{2}}\left(\omega_{i 2}-\beta_{i 2}\right) x_{i 2}+\sum_{d=1}^{s} \pi_{d} z_{d}=1 \\
& L_{i 2 j}^{1} \omega_{i 2} \leq \beta_{i 2 j} \leq L_{i 2 j}^{2} \omega_{i 2}, j=1,2,3, \cdots, n \\
& \mu_{r}, \pi_{d}, \omega_{i 1}, \omega_{i 2} \geq \varepsilon, i_{1} \in I_{1}, i_{2} \in I_{2}, r=1,2, \cdots, t, d=1,2, \cdots, s
\end{aligned}
$$

The calculation of the above model can obtain the efficiency score of the second stage. Bring the efficiency of the second stage into the formula

$$
\theta_{1}^{*}=\frac{\theta_{0}^{\prime \prime}-\theta_{2}^{\prime \prime} \omega_{2}^{\prime \prime}}{\omega_{1}^{\prime \prime}}
$$

Then, the efficiency value of the first stage is obtained.

Based on the evaluation model constructed, 10 innovation-oriented cities in Yangtze River Delta urban agglomeration like Nanjing, Hefei and Changzhou, Wuxi, Hangzhou, Shanghai etc. is empirically evaluated and the gap between each other and the insufficiency are discovered.

\section{Empirical Analysis of Evaluation Model-Taking Innovation-Oriented Cities in Yangtze River Delta as Examples}

As the most intensified region with innovation-oriented cities in China, the Yangtze River Delta has strong guiding significance for the construction of innovation-oriented cities in other areas of China. Therefore, this paper focuses on the advantages and existing problems and puts forward some countermeasures and suggestions for the construction of innovation-oriented cities in Yangtze River Delta. The study data are mainly from the Statistical Yearbook of Chinese Cities, the statistical yearbook of each city, the scientific and technological yearbook and the public data of the municipal science and technology bureau.

Combining the model's requirement for hysteresis of data, under the premise of ensuring data's availability and representativeness, the research set the year of 2013 as the base of the current phase. The two-year hysteresis of the output data adopts other cities' indicator data in 2015 and innovative input data in t-1 phase use cities' data in 2012 so that the DEA's basic requirement for the sample can be met. 


\subsection{Principal Component Analysis}

The essence of the principal component analysis is a process of dimension reduction. It classifies multiple interrelated indicators and extracts the main ingredients to reflect the main characteristics of a certain indicators, which is the main way to reduce number of variables. Factor analysis was conducted to test the validity of scales and ensure that questionnaire contents and structure are effective [11]. Through main factor analysis, the multiple variables are adjusted into fewer variables. We cut the relationship between those fewer variables so that they can reflect the information of the indicators to the uttermost. The main approach adopted by principal component analysis is accumulated to explain variance sum. Namely, if the cumulative interpretation variance of the selected principal component is more than $70 \%$, we just keep the extracted principal component as general representative of the indicators. When building the indicator system in this paper, a total of three secondary indicators, 11 third-level indicators and 44 third-level indicators are established. In order to make the data envelopment analysis (DEA) has a simple calculation and a simplified model, we focus on main factor analysis from 11 three-level indicator to 44 four-level indicators and extract the variable reflecting a three-level indicator and then explain the variance changes of the third-level indicator to a great extent. Here we will conduct principal component analysis on the four-level indicators from the dimension of 11 third-level indicators. Since both third-level indicators have defects when the intermediary platform constructing their data and the variables of industry-university-research cooperation are relatively small, those two third-level indicators will not be extracted for principal component and the original fourth-level indicators will be kept. The results of principal component analysis via SPSS software are as Table 2.

\subsection{Empirical Findings}

Based on results of principal component analysis, five input indicators, 6 output indicators and 5 intermediate variables are extracted from all indicator variables. They will be evaluated on their innovation efficiency according to the model design. The data is imported into Matlab and the unknown parameters in the model can be solved in an optimization algorithm way. The results are shown in Table 3 and Table 4.

The effectiveness of DEA mainly refers to how to maximize the input and output ratio in the system, namely the maximum efficiency of input and output. Therefore, the effectiveness analysis can reflect whether the input and output of a region is reasonable or not and the regional innovative development efficiency to some extent. The effectiveness of the urban innovation development can be evaluated through the comparison among cities' overall innovation efficiency. Compared with cities with low innovative efficiency, the overall innovation system operation of cities with high innovative efficiency are more effective. DEA model can determine the effectiveness of technology and scale at the same time. 
Table 2. Principal Factors Analysis of Capital Input Indicators.

\begin{tabular}{|c|c|c|c|c|c|c|}
\hline \multicolumn{7}{|c|}{ Total Variance of Interpretation } \\
\hline \multirow[b]{2}{*}{ Indicator's Name } & \multicolumn{3}{|c|}{ Initial Eigenvalues } & \multicolumn{3}{|c|}{ Extract and Load Quadratic Sum } \\
\hline & Sum & $\begin{array}{c}\% \text { of } \\
\text { Variance }\end{array}$ & $\begin{array}{c}\% \text { of } \\
\text { Accumulation }\end{array}$ & Sum & $\begin{array}{c}\% \text { of } \\
\text { Variance }\end{array}$ & $\begin{array}{c}\% \text { of } \\
\text { Accumulation }\end{array}$ \\
\hline $\begin{array}{c}\text { Capital Input Indicator } \\
\mathrm{KMO}=0.79, \text { Chi-Square }=26.69, \mathrm{Sig}=0.000\end{array}$ & 3.29 & 82.48 & 82.48 & 3.299 & 82.48 & 82.48 \\
\hline $\begin{array}{c}\text { Innovative Talent Input Indicator } \\
\mathrm{KMO}=0.72, \text { Chi-Square }=24.10, \mathrm{Sig}=0.001\end{array}$ & 2.822 & 70.546 & 70.546 & 2.822 & 70.546 & 70.546 \\
\hline \multirow[t]{2}{*}{$\begin{array}{l}\text { Innovative Environmental Construction Indicator } \\
\mathrm{KMO}=0.648, \mathrm{Chi}-\mathrm{Square}=31.56, \mathrm{Sig}=0.000\end{array}$} & 2.990 & 59.810 & 59.810 & 2.990 & 59.810 & 59.810 \\
\hline & 1.016 & 20.322 & 80.132 & 1.016 & 20.322 & 80.132 \\
\hline $\begin{array}{l}\text { Innovative Policy Indicator } \mathrm{KMO}=0.773 \text {, Chi-Square }=54.788 \text {, } \\
\qquad \mathrm{Sig}=0.000\end{array}$ & 3.688 & 92.203 & 92.203 & 3.688 & 92.203 & 92.203 \\
\hline $\begin{array}{l}\text { Innovative Absorption of Diffusion Indicator } \\
\mathrm{KMO}=0.693, \text { Chi-Square }=46.22, \mathrm{Sig}=0.000\end{array}$ & 3.513 & 87.813 & 87.813 & 3.513 & 87.813 & 87.813 \\
\hline $\begin{array}{l}\text { Scientific and Technological Innovation Performance Indicator } \\
\qquad \mathrm{KMO}=0.747, \text { Chi-Square }=14.74, \mathrm{Sig}=0.002\end{array}$ & 2.543 & 84.766 & 84.766 & 2.543 & 84.766 & 84.766 \\
\hline $\begin{array}{l}\text { Economy Development Performance Indicator } \\
\mathrm{KMO}=0.744, \text { Chi-Square }=48.214, \mathrm{Sig}=0.000\end{array}$ & 2.543 & 84.766 & 84.766 & 2.543 & 84.766 & 84.766 \\
\hline \multirow[t]{2}{*}{$\begin{array}{l}\text { Social Contribution Performance Indicator } \\
\mathrm{KMO}=0.640, \text { Chi-Square }=21.989, \mathrm{Sig}=0.001\end{array}$} & 2.713 & 67.836 & 67.836 & 2.713 & 67.836 & 67.836 \\
\hline & 1.012 & 25.298 & 93.134 & 1.012 & 25.298 & 93.134 \\
\hline Innovative Talent Input Indicator & 2.246 & 44.915 & 44.915 & 2.246 & 44.915 & 44.915 \\
\hline $\mathrm{KMO}=0.435$, Chi-Square $=24.200, \mathrm{Sig}=0.007$ & 1.813 & 36.263 & 81.178 & 1.813 & 36.263 & 81.178 \\
\hline
\end{tabular}

Table 3. Prioritized Efficiency Results of Stage I (CRS).

\begin{tabular}{ccccccccccccc}
\hline DMU & $\theta_{0}^{*}$ & $\theta_{1}^{*}$ & $\theta_{2}^{*}$ & $w_{1}^{*}$ & $w_{2}^{*}$ & $\alpha_{1}^{*}$ & $\alpha_{2}^{*}$ & $\alpha_{3}^{*}$ & $\alpha_{4}^{*}$ & $\alpha_{5}^{*}$ \\
\hline Hefei & 1.000000 & 1.000000 & 1.000000 & 0.237643 & 0.762357 & 0.305041 & 0.309870 & 0.304305 & 0.302066 & 0.3140558 \\
Shanghai & 0.689051 & 1.000000 & 0.489333 & 0.391093 & 0.608907 & 0.498193 & 0.341109 & 0.528939 & 0.503456 & 0.5566682 \\
Nanjing & 0.635088 & 0.813794 & 0.510410 & 0.410957 & 0.589043 & 0.300000 & 0.700000 & 0.700000 & 0.300000 & 0.3000000 \\
Wuxi & 0.882346 & 0.543985 & 0.999948 & 0.257920 & 0.742080 & 0.300854 & 0.300000 & 0.300000 & 0.300001 & 0.3000000 \\
Hangzhou & 0.732592 & 1.000000 & 0.551071 & 0.404343 & 0.595657 & 0.563261 & 0.629721 & 0.637628 & 0.533378 & 0.6204756 \\
Ningbo & 0.747661 & 0.126858 & 1.000000 & 0.289001 & 0.710999 & 0.300000 & 0.300000 & 0.300000 & 0.300000 & 0.3000000 \\
Jiaxing & 0.888720 & 0.566073 & 1.000000 & 0.256449 & 0.743551 & 0.300000 & 0.300000 & 0.300000 & 0.300000 & 0.3000000 \\
Suzhou & 1.000000 & 1.000000 & 1.000000 & 0.363663 & 0.636337 & 0.553542 & 0.622925 & 0.636851 & 0.545490 & 0.4838818 \\
Yangzhou & 0.937168 & 0.743890 & 0.999978 & 0.245269 & 0.754731 & 0.302536 & 0.300045 & 0.300000 & 0.300005 & 0.3000015 \\
Yancheng & 0.970325 & 0.875165 & 0.999984 & 0.237617 & 0.762383 & 0.300000 & 0.300000 & 0.300000 & 0.300001 & 0.3000001 \\
\hline
\end{tabular}


Table 4. Prioritized Efficiency Results of Stage II (CRS).

\begin{tabular}{|c|c|c|c|c|c|c|c|c|c|c|}
\hline DMU & $\theta_{0}^{*}$ & $\theta_{1}^{*}$ & $\theta_{2}^{*}$ & $w_{1}^{*}$ & $w_{2}^{*}$ & $\alpha_{1}^{*}$ & $\alpha_{2}^{*}$ & $\alpha_{3}^{*}$ & $\alpha_{4}^{*}$ & $\alpha_{5}^{*}$ \\
\hline Hefei & 1.000000 & 1.000000 & 1.000000 & 0.237643 & 0.762357 & 0.418681 & 0.410633 & 0.377760 & 0.479513 & 0.43892934 \\
\hline Shanghai & 0.689051 & 0.374186 & 0.891286 & 0.391093 & 0.608907 & 0.700000 & 0.700000 & 0.700000 & 0.700000 & 0.69999999 \\
\hline Nanjing & 0.635088 & 0.112042 & 1.000000 & 0.410957 & 0.589043 & 0.540047 & 0.437427 & 0.346135 & 0.614270 & 0.69666214 \\
\hline Hangzhou & 0.732592 & 0.916977 & 0.607429 & 0.404343 & 0.595657 & 0.697542 & 0.700000 & 0.700000 & 0.700000 & 0.70000000 \\
\hline Ningbo & 0.747661 & 0.126858 & 1.000000 & 0.289001 & 0.710999 & 0.300000 & 0.300000 & 0.300000 & 0.300000 & 0.30000000 \\
\hline Jiaxing & 0.888720 & 0.566073 & 1.000000 & 0.256449 & 0.743551 & 0.300000 & 0.300000 & 0.300000 & 0.300000 & 0.30000000 \\
\hline Suzhou & 1.000000 & 1.000000 & 1.000000 & 0.363663 & 0.636337 & 0.566017 & 0.571626 & 0.582256 & 0.547961 & 0.57969228 \\
\hline Yangzhou & 0.937168 & 0.743838 & 0.999995 & 0.245269 & 0.754731 & 0.300000 & 0.300000 & 0.300000 & 0.299999 & 0.29999999 \\
\hline Yancheng & 0.970325 & 0.875114 & 1.000000 & 0.237617 & 0.762383 & 0.300000 & 0.300005 & 0.300001 & 0.304968 & 0.30838929 \\
\hline
\end{tabular}

The optimal solution of the model, namely the innovative efficiency, is the most direct indicator to show the effectiveness. When $\theta=1$, a DMU decision-making unit is effective for the DEA. When $\theta \neq 1$, a DMU decision-making unit is effective for non-DEA.

Therefore, the above table embodies the innovation efficiency value of $10 \mathrm{ci}$ ties. It can be seen from the data in the table that Hefei and Suzhou overall innovation performance $\theta$ is 1 whether it is the preference of the first stage or the second stage. That shows the city innovation system efficiency DEA is effective and realizes the technology effectiveness. Compared with the above cities, the total innovation efficiency of other cities has not reached 1 , which is effective for non-DEA, indicating that there is an unreasonable allocation between innovation input and output in the region. On the efficiency results of the first stage preference, the overall inefficiency of Shanghai and Hangzhou is low, mainly due to the low efficiency of the second stage. The efficiency of Nanjing, Wuxi, Ningbo, Jiaxing, Yangzhou and Yancheng is ineffective on both stages. On the efficiency results of second stage preference, the overall inefficiency of Nanjing, Wuxi, Ningbo, Jiaxing and Yancheng is ineffective because of the low efficiency of the first stage, while Shanghai, Hangzhou and Yangzhou are ineffective on both stages.

\section{Conclusion and Discussion}

From individual efficiency on two stages, on the first stage of priority model, Shanghai's overall efficiency is low, mainly due to the low efficiency on the second stage, which is the main reason for Shanghai's low ranking on overall innovation efficiency in the 10 cities. Compared with another 9 cities, Shanghai was in scientific and technological resources endowment, regional environment, talent advantage and development base, etc. However, Shanghai's urban development is more dependent on innate developmental advantages like traffic and 
resource. From the specific data of the final output indicators, it can been that Shanghai has no obviously sufficient advantages in ecological environment construction and social driving ability, which especially show in Shanghai's industrial development energy consumption, waste treatment and utilization and unemployment rate, etc. It can be seen that developed cities face more severe urban pressures than other cities in the process of innovative development and urban problems are more prominent. From the perspective of the specific weight of the two links, whether it is the first stage preference or the second stage preference, Shanghai always gives greater weight on the innovation efficiency on the second stage. Tt also suggests that Shanghai needs to pay attention to ecological environment and social development indicators, intensively solve environmental problems and employment problems and avoid decreasing returns to scale caused by innovation input redundancy if it wants to improve the existing innovation efficiency. The innovation efficiency on the first stage and the second stage is low. However, when seen from two different priority models, the low innovation efficiency on the first stage has outstanding influence on the overall innovation efficiency; the initial innovation input has no significant impact on intermediary measures, which especially reflects in related expenditures and technology import, transformation and purchase budget spending on industry-university-institute cooperation. Compared with other cities within the province, Suzhou, Wuxi, Yangzhou and Yancheng have realized the effective DEA in overall efficiency, which shows that there is a waste of resources or insufficient input of resources in some areas of Nanjing city during the process of the innovation-oriented city construction. Through comparison between two-stage model, Hangzhou's capital input like R\&D input accounts for a larger proportion in both stages in the process of innovation, which indicates that increasing capital input will improve the existing innovation efficiency under the premise of increasing scale economy. But its overall efficiency is low and there are existing problems as follow: First, Hangzhou has a weak market environment, especially the export environment. The pull ability of the external consumption demand is not strong. Although there are big companies like Alibaba, it has no obvious port transportation advantage when compared with Ningbo in the same province. Second, Hangzhou has the lowest case settlement rate in the whole region, which is related to the lawsuit between locally active private lending and developed small commodity economy. The external environment has impact on the construction of technological innovation, technological achievement transformation and innovation network. Third, Hangzhou has a developed commodity economy and more foundry enterprises. Those enterprises have low innovation ability as a whole, a low investment in industry-university-research cooperation and a low participation enthusiasm in innovation. Fourth, the government's conducts an insufficient investment in education and scientific research; the innovation policy has a weak incentive effect; the tax deduction for enterprises and research is low. 
The above problems show that relevant cities should consider not only scientific and technological innovation but also economic benefits, social benefits and ecological benefits in the process of constructing national innovation-oriented cities in the future. The construction of a service-oriented government shall be further strengthened; more strengthen shall be devoted into streamlining administration and delegating power to the lower levels; restrictions on innovative entrepreneurial activities shall be reduced; support for cities' innovative developments shall be strengthened; an atmosphere of multi-participation into innovation-oriented city construction shall be created in the whole society. The working coordination mechanism should be established and improved; resources should be integrated for city development; formation into the joint effort among relevant departments and units should be improved practically; the holistic innovation-oriented city construction system should be coordinated and planned with a clear target around main objectives and key tasks for the construction of an innovation-oriented city. Simultaneously, government should strengthen the perfection on supporting measures, earnestly implement the policy system to support industrial development, intensify education, science, and technology spending and promote basic researches and common researches through input of R\&D funds. In terms of capital input, it is necessary to build financial innovation system, deepen capital market construction, improve support to innovative entrepreneurship and strengthen scientific and technological financial service ability to meet developing demand of scientific technologyoriented enterprises. Innovate financial institutions' management system, establish and improve venture capital market and expand financing channels for innovation-oriented enterprises. We will actively promote Internet finance development, encourage and guide the establishment and development of intermediary institutions that promote scientific and technological innovation and financial services and continue to promote the improvement of tax financing and government-bank-guarantee institution cooperation mechanisms. To encourage the provision of corresponding credit lines to key research projects and scientific research achievements transformation projects. Government guides commercial banks to support R\&D and innovation of enterprises, encourages the credit and loan, set up special funds to support scientific and technological achievements transformation, encourage commercial banks to increase support in this field and encourage financially key areas where science and technology are concentrated and organizations and projects in those related industry. There is no need to go into detail on how important social network analysis has become across a wide landscape of disciplines [12]. In addition, we should vigorously promote the development of various investment methods, such as equity investment and angel investment, and encourage enterprises to adopt diversified financing methods. We will promote R\&D and financial capital cooperation of scientific technology-oriented industries; strengthen investment and R\&D in key innovative enterprises and support innovation and entrepreneurship in capital. 
Seen from empirical results in Yangtze River Delta region, many cities with significant economic efficiency and technological innovation have met a reduction in their innovation efficiency after considering social indicators and ecological indicators. This shows that adjustment of industrial structure should be speeded up and the development of independent entrepreneurship and innovative small and medium-sized enterprises should be encouraged so that social employment opportunities can be improved during the construction of innovationoriented cities. Simultaneously, enterprises should strengthen their commitment on social responsibility, promote employment through innovation, actively participate in social welfare and social relief, accelerate the recovery of labor force and lead the unemployed to be re-employed. In addition, accelerate the optimization and upgrading of industrial structure, transform economy growth mode, make full use of technological innovation to cultivate and support new energy industry and improve resource utilization efficiency. We will increase supervision and punishment on enterprises' pollution discharge, promote the use of energy-efficient equipment and pollution control equipment and accelerate ecological civilization construction in cities.

\section{References}

[1] Jin, J., Gubbi, J., Marusic, S. and Palaniswami, M. (2014) An Information Framework for Creating a Smart City through Internet of Things. Internet of Things Journal, 1, 112-121. https://doi.org/10.1109/JIOT.2013.2296516

[2] Scott, A.J. (2006) Creative Cities: Conceptual Issues and Policy Questions. Journal of Urban Affairs, 28, 1-17. https://doi.org/10.1111/j.0735-2166.2006.00256.x

[3] Hekkert, M.P., Suurs, R.A.A. and Negro, S.O. (2007) Functions of Innovation Systems: A New Approach for Analysing Technological Change. Technological Forecasting \& Social Change, 74, 413-432.

[4] Leydesdorff, L. (2005) The Triple Helix Model and the Study of Knowledge Based Innovation Systems. International Journal of Contemporary Sociology, 42, 12-27.

[5] Cowan, R., Jonard, N. and Zimmermann, J.B. (2007) Bilateral Collaboration and the Emergence of Innovation Networks. Management Science, 53, 1051-1067. https://doi.org/10.1287/mnsc.1060.0618

[6] Huang, Y.L., Lu, J. and Tang, L.R. (2002) The Study on Transforming Achievements of Technological Innovation into Intellectual Property. Soft Science, 53, 101-107.

[7] Porter, M.E. (1990) The Competitive Advantage of Nations. Free Press, New York.

[8] Hansen, B. (2007) The Innovation Value Chain. Harvard Business Review, 85, 121.

[9] Olcay, G.A. and Bulu, M. (2014) Assessing the Role of Technology Transfer Offices for Being an Innovative City: The Case of Istanbul. Kcws.

[10] Engel, J.S. and Del-Palacio, I. (2011) Global Clusters of Innovation: The Case of Israel and Silicon Valley. California Management Review, 53, 27-49. https://doi.org/10.1525/cmr.2011.53.2.27

[11] Gronlund, N.E. and Linn, R.L. (1990) Measurement and Evaluation in Teaching. McMillan Company, New York.

[12] Danowski, J.A. (2010) Identifying Collaborative Innovation Networks-At the Inter-Departmental Level. Procedia-Socialand Behavioral Sciences, 2, 6404-6417. 
Submit or recommend next manuscript to SCIRP and we will provide best service for you:

Accepting pre-submission inquiries through Email, Facebook, LinkedIn, Twitter, etc. A wide selection of journals (inclusive of 9 subjects, more than 200 journals)

Providing 24-hour high-quality service

User-friendly online submission system

Fair and swift peer-review system

Efficient typesetting and proofreading procedure

Display of the result of downloads and visits, as well as the number of cited articles Maximum dissemination of your research work

Submit your manuscript at: http://papersubmission.scirp.org/

Or contact jamp@scirp.org 